\title{
Archaeometry, a Discipline for Linking Archaeology to Natural Science \\ (Aims and Scopes)
}

\author{
S.M.A. EMAMI* \\ Assist. Prof. Dr. rer. nat. in mineralogy and crystallography, Art University of Isfahan, IRAN
}

\begin{abstract}
In the last decade, increasing and develop of the scientific discipline such as science, engineering and medicine was considerable. With respect to this point of view, nowadays, comparative and interdisciplinary disciplines are also collaborated to each other. Archaeological investigations followed by related scientific methods would try to get answer to the problems which were mentioned by archaeologists due to the know-how in antiquity. Archaeometry means, the use of new instrumental, statistical methods for interpreting the technology based on collected archaeological data. In another word, archaeometry is a methodology for data management which has been collected via different expertise of each scientific discipline. Archaeometrical studies focus mostly on generate and development of common language for linking human science with another discipline such as science, engineering and medicine.
\end{abstract}

Keywords: Archaeometry, Archaeology, Interdisciplinary methods.

\footnotetext{
* - Corresponding author: emami@chemie.uni-siegen.de
} 


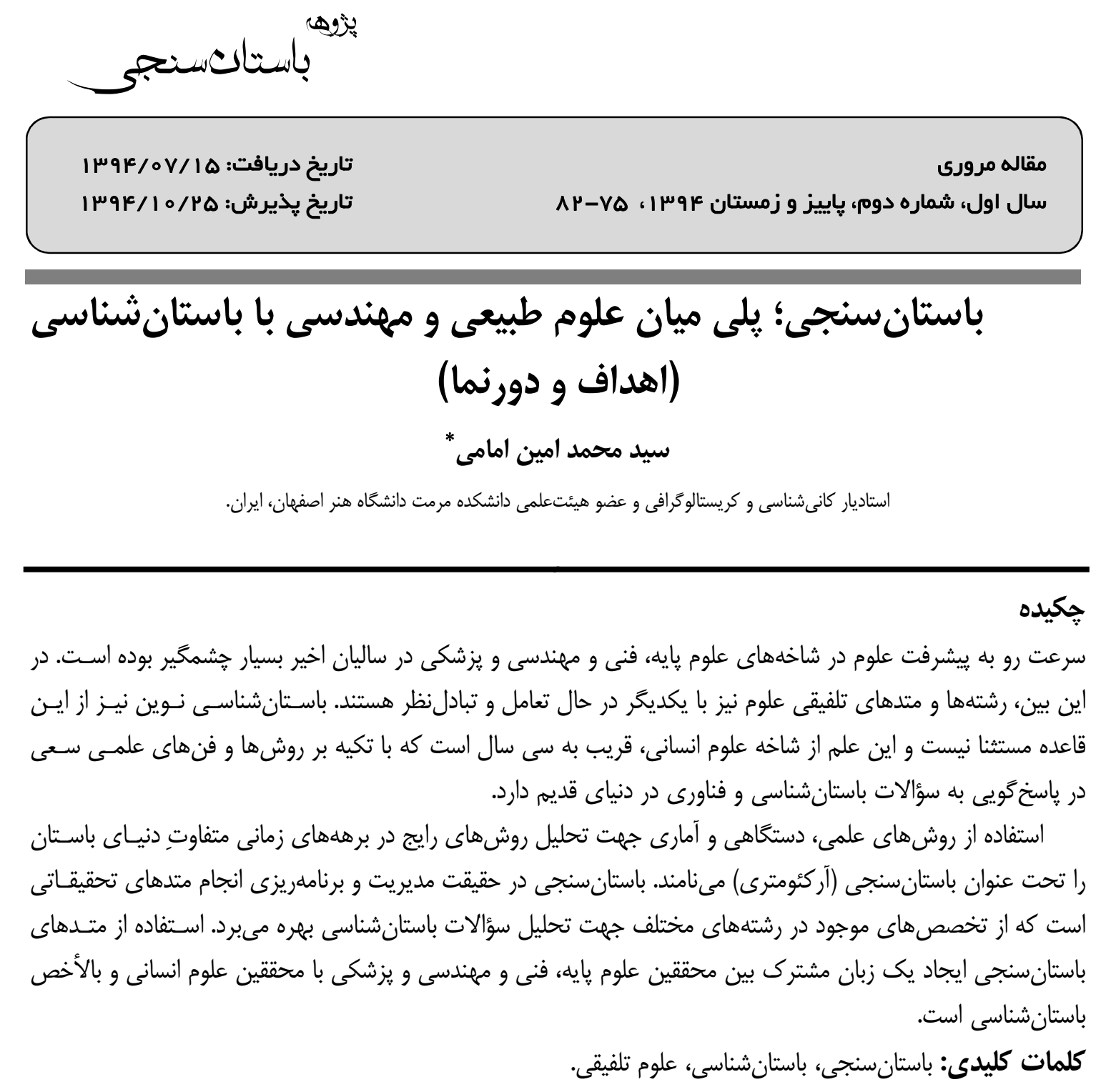

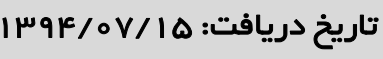

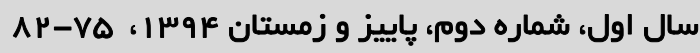

كلمات كليدى: باستانسنجى، باستانشناسى، علوم تلفيقى.

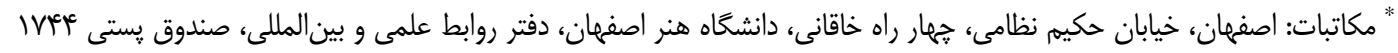

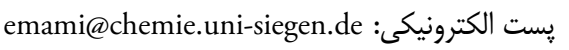
C) حق نشر متعلق به نويسنده(كان) است و نويسنده تحت مجوز Creative Commons Attribution License به مجله اجازه مىدهد مقاله خاب شده را با ديكران به اشتراك بكذارد منوط بر اينكه حقوق مؤلف اثر حفظ و به انتشار اوليه مقاله در اين مجله اشاره شود. 
سؤالات مورد بحث در باستانشناسى امروزه (از دهـــــ •م ه.ش) شامل شناسايى ابزار، تكنيكهاى ساخت مواد و

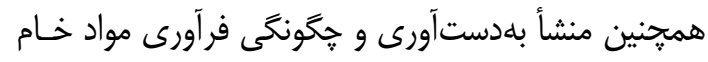

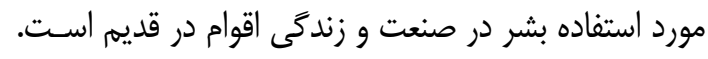

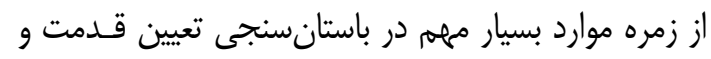

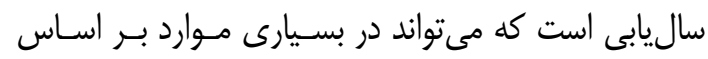
مدلهاى زئوشيميايى بيانكر اصالت شىء مورد مطالعه نيز

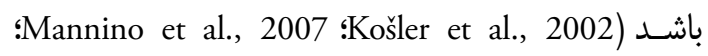

.(Willmott et al., 2012 رشته باستانسنجى در كشورهاى ييشرفته و در حـال

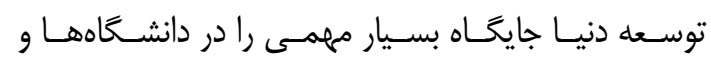

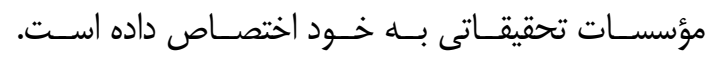

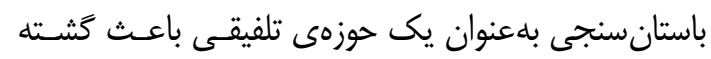

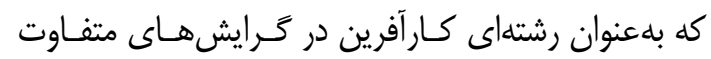
يزوهشى مورد توجه قرار گيرد. باستان سنجى مجموعه مطالعات منظمى است بـراى

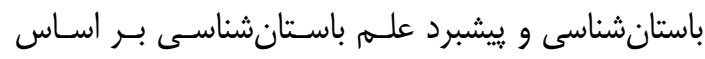

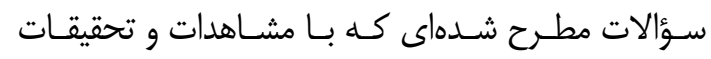

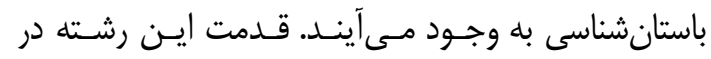

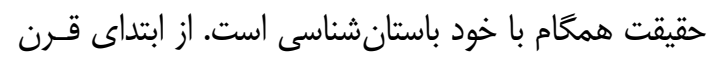

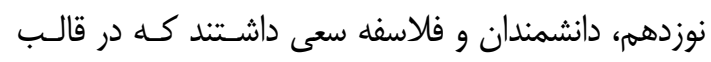
مبانى نظرى باستانشناسى تعريفى از اين رشته ارائه دهند

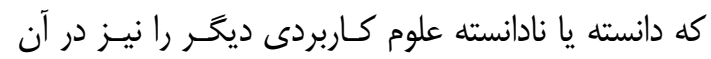

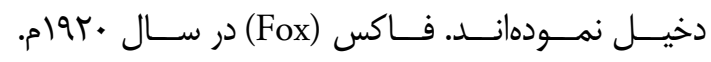

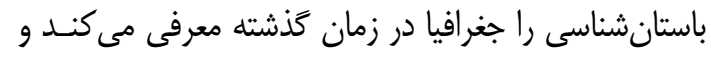

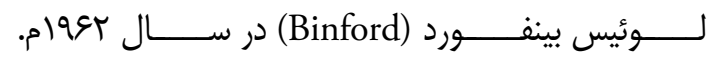

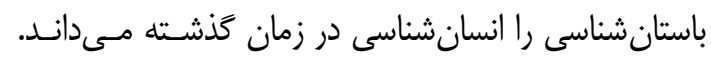

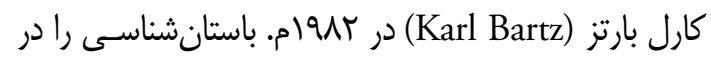

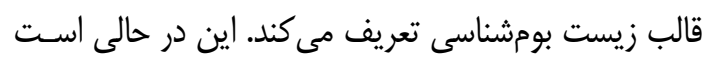

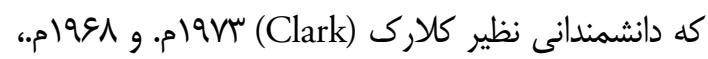

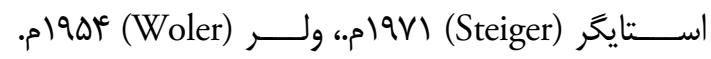

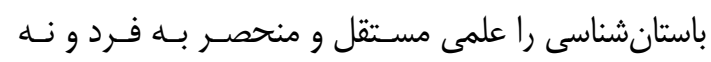

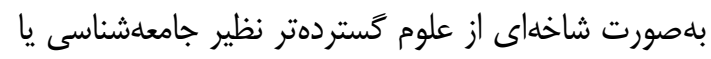

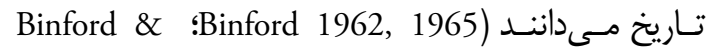

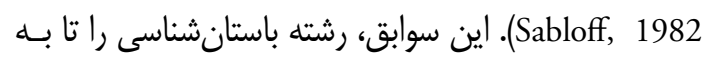

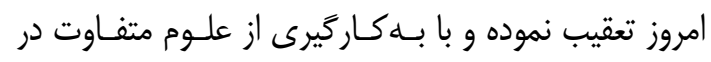

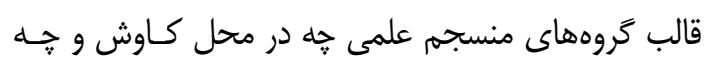

| - (- مقدمه

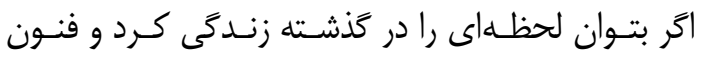

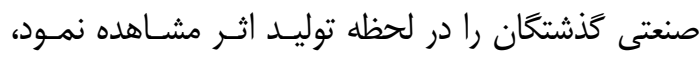

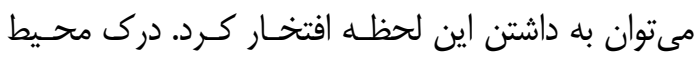

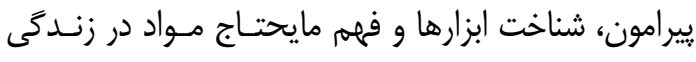

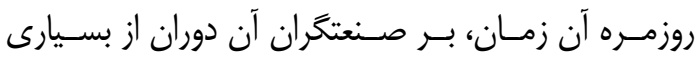

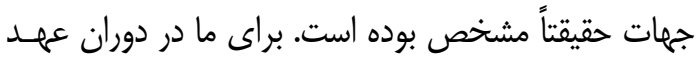

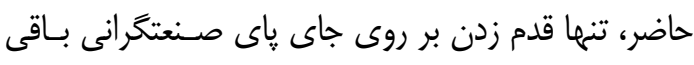
مانده است كه پايه فنآورى را استوار كردند.

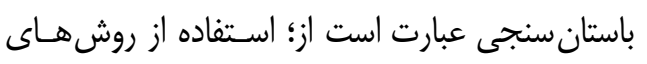

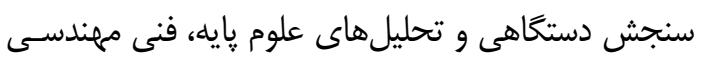

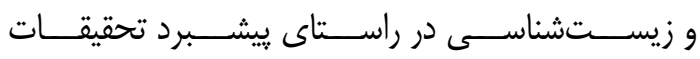

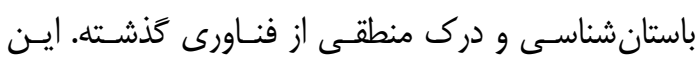

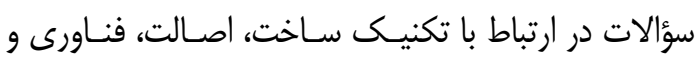

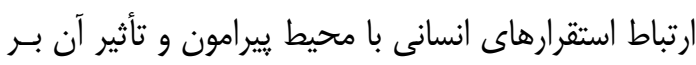

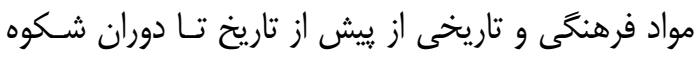
هنر اسلامى است.

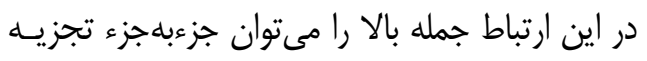

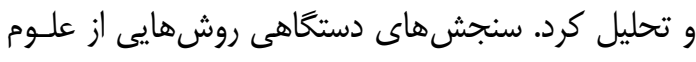

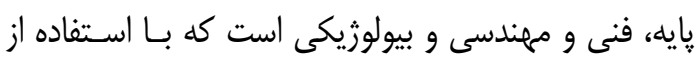

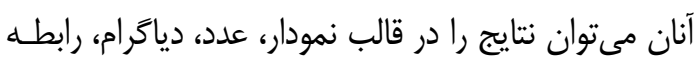

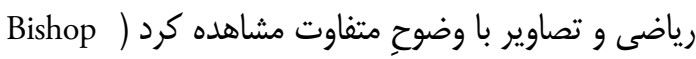
Lichtensteiger et ؛Hauptmann, 1985 ؛tet al., 1982

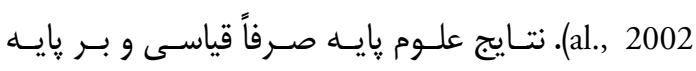

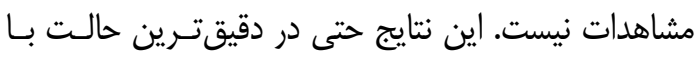

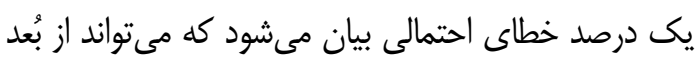

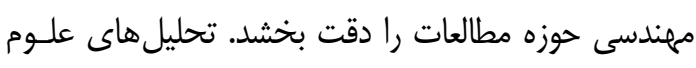

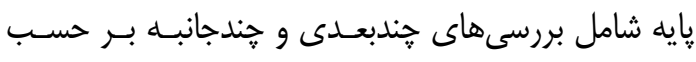

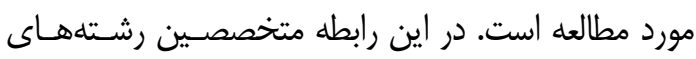

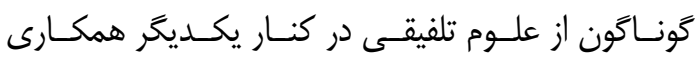

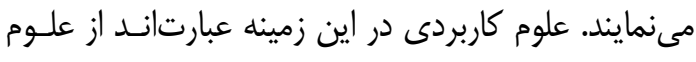

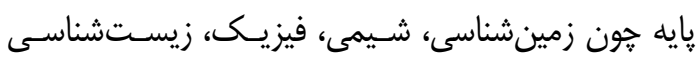

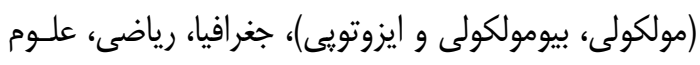

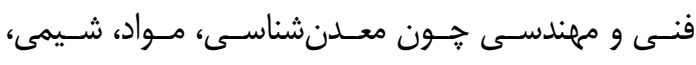

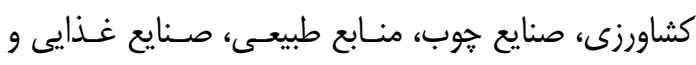

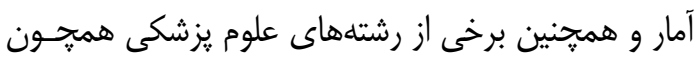

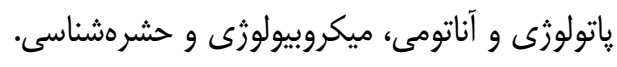

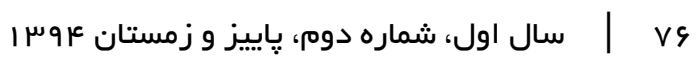


Zoo (archaeological bone)

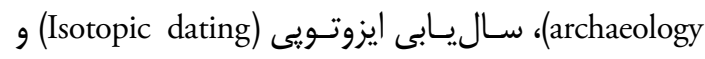

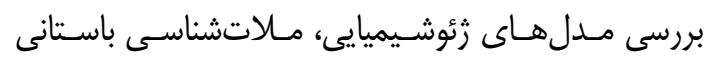

روشهاى به كار گرفتـه شــه همـواره ابزارهـايى در

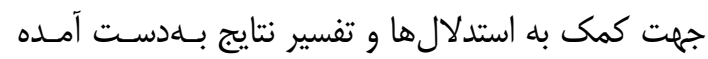

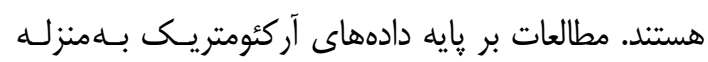

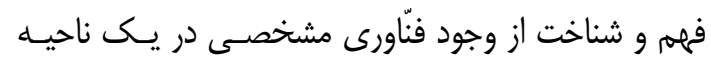

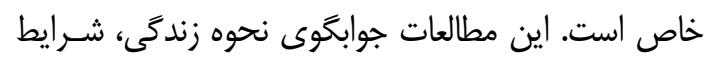

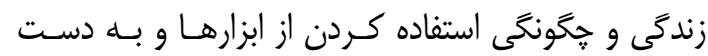

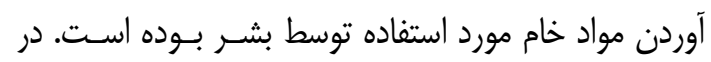

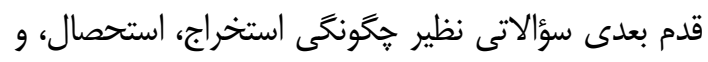

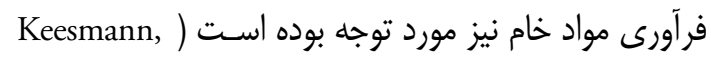
Giumlia-Mair, ؛Bachmann \& Hauptmann, 1984a 2001). مطالعات آركئومتريكى ارتبـاط تمـدنهــا را از بُعـد

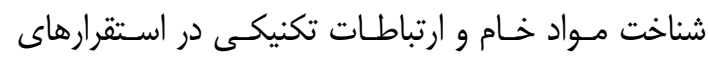
متفاوت مورد بررسى قرار مىدهد. در اين راستا با توجه به

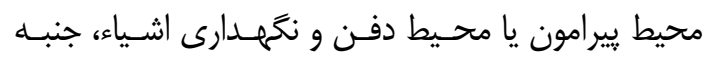
ساختارى مواد همجون فن شناسـى و آسـيبشناسـى نيـز

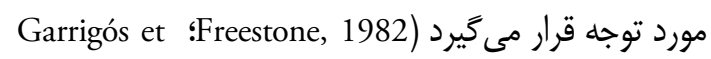
Emami \& Trettin, ؛Emami et al., 2008 ؛al., 2003

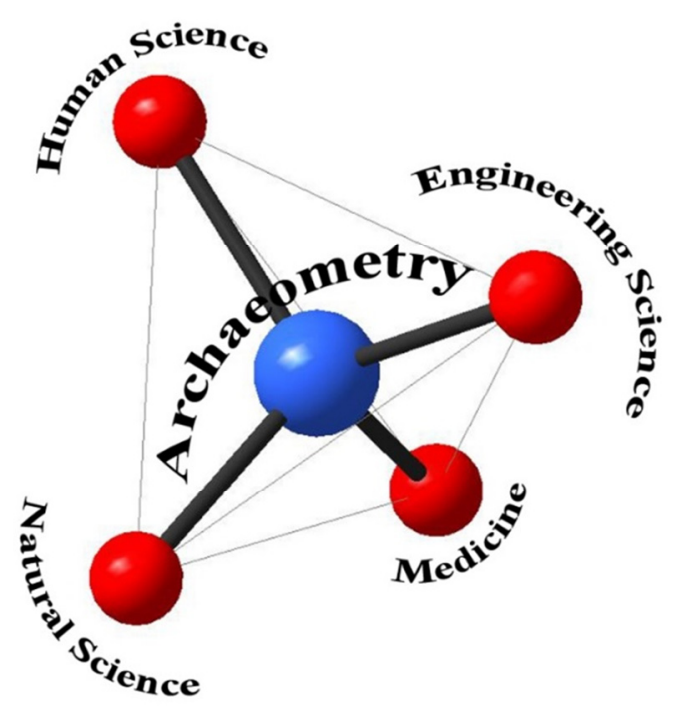

شكل ا. نمودار مربوط به وابستكى علوم متفاوت در قالب آركئومترى يا باستانسنى علىم متفات

vV سال اول، شماره دوم، ياييز و زمستان عq س |
در آزمايشگاهها، به سـؤالات باسـتانشناسـان پاسـخ داده

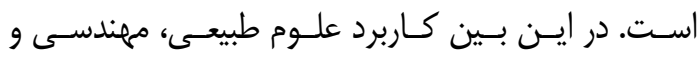

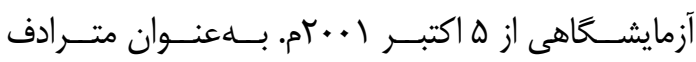

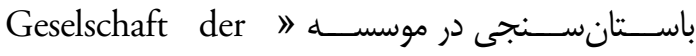
Natutwissenschaftliche und Analytische در كشور آلمان مورد اسـتفاده (GNAA) «Archaeology

$$
\text { قرار مى گيرد. }
$$

\section{r - تعاريف و اهداف مطالعات آركئومترى}

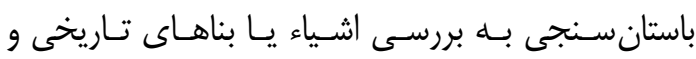

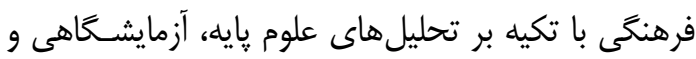
علوم زيستى و حتـى ثزشـكى يرداختـه و باعـث شــاخت

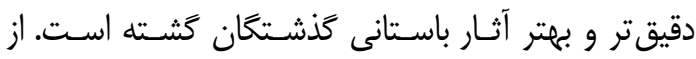
اهداف اصلى باستان سنجى مى توان بــه نحــوه بــهـ وجـود

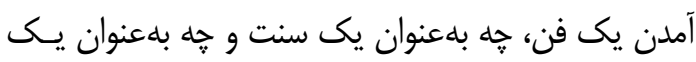

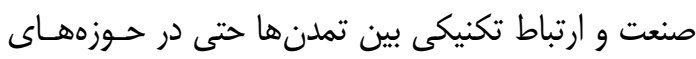

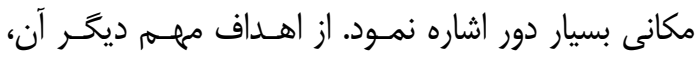
ايجاد فضايى مناسب جهت همكارىهاى بينرشـتهاى در

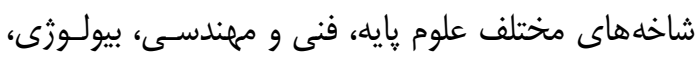

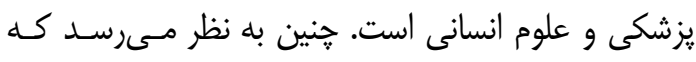
باستانسنجى يكى زبــان مشـترك اسـت، زبــان اسـير انتو بين محققين علوم پايـه، مهندسـى و علـوم (Esperanto) انسانى است. با توجه به اينكه كشور ما در يك شاهراه بسيار مهـم بين شرق و غرب قرار داشـته و همجنـين داراى يتانسـيل

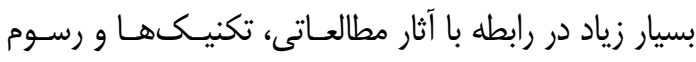

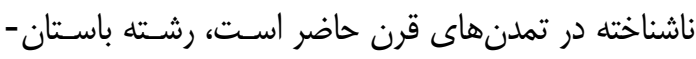

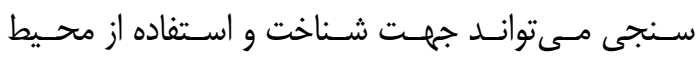
ييرامون، از جذابيتهاى خاصى برخوردار باشد.

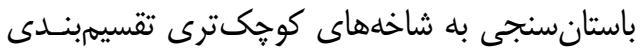

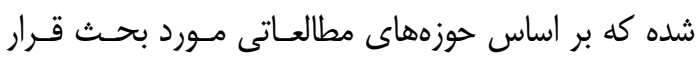

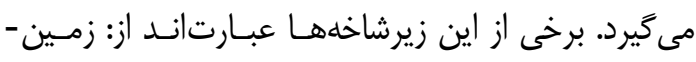

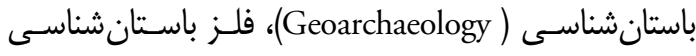
Archaeo-) (Archaeometallurgy) (Geophysics

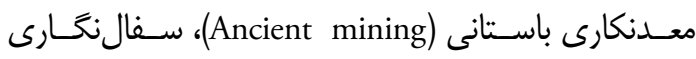

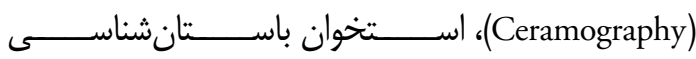


9. شناسايى انغل هـا، قـارجهـا و بـاكترىهـايى كـهـ از

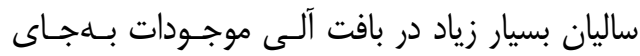

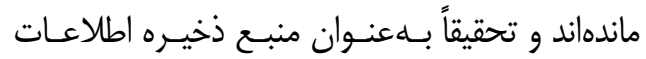

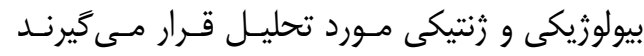
.(Reinhard, 1992) سابقه مطالعات باستان سنجى در ايران بر حسب مورد

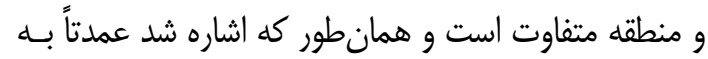

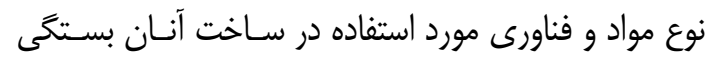

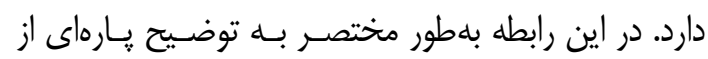
موارد مورد بحث در باستان سنجى مى يردازيم. بـا مطالعـه

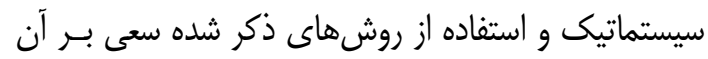
ست كه به سؤالات زير ياسخ داده شود؛

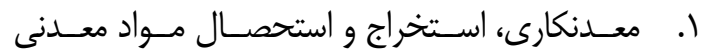
بلهعنوان يك تخصـص هـدفدار در يـى محـدوده تاريخى. ك. روش هاى فرآورى و بعينهسازى مواد و مصالح آلى و معلى و קُكَونكى استفاده از آنها.

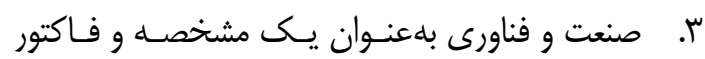

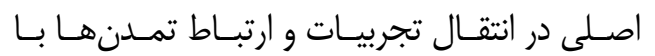
يكديگر.

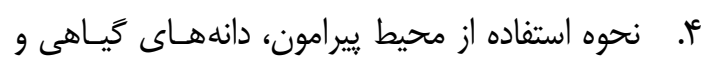

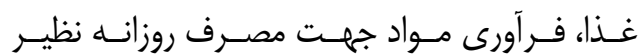
منسوجات و يوشاك، و نيز جَكَنكَى استفاده از مـواد آلى موجود در طبيعت نظير خوب.

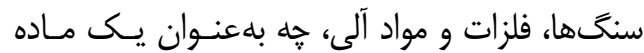

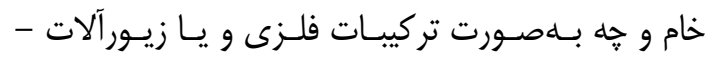

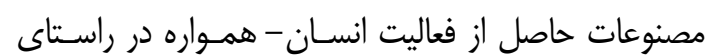
ييشرفت تمدن نقش عمدهاى را بازى كردهانـــ اسـتخراج

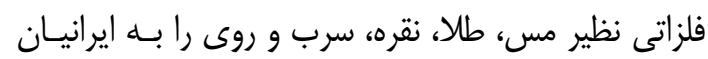

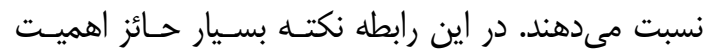
وجود سربارههايى است كه اثبات كننده مراحل آليازرسازى

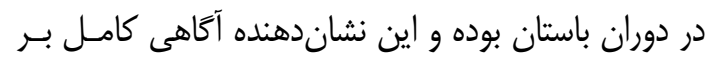
روى خصوصيات ساختارى فلزات در جهت استخراج آنسان بـن بـان

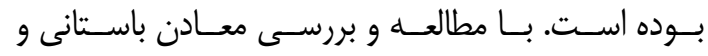

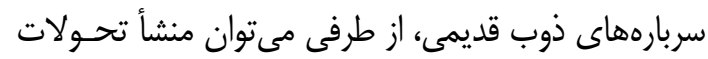

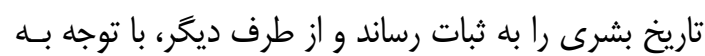

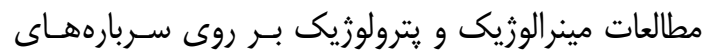

\section{" آ- موضوعات باستانسنجى}

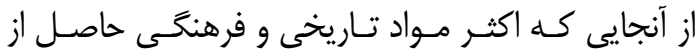
حفارى هاى باستانشناسى و ماحصل دست بشر و تفكر او او

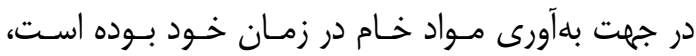

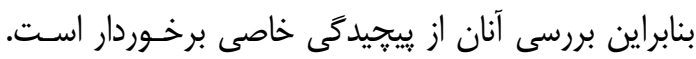

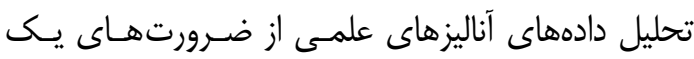

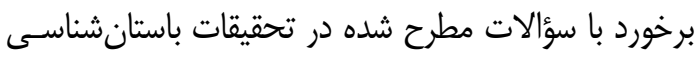
است. اين تحقيقات بيشتر در دو حـالات كلى بـ شناسـايى

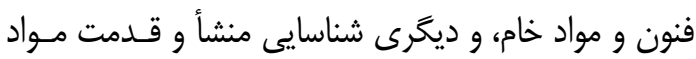

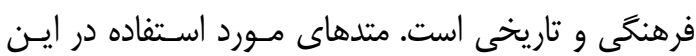
خصوص بيشتر شامل:

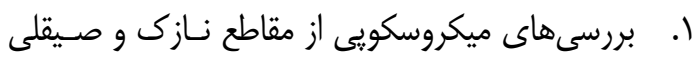

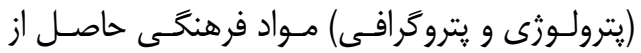
كـاوشهــاى باسـتانشناسـى (Riederer, 2004) .(Emami \& Trettin, 2013 r. نتايج حاصـل از آزمـايشهـاى شـيمى كلاسـيك و شيمى دستخاهى (Duminuco et al., 1998؛ .Fernández et al., 2015 set al., 2015 ". بررسـى و مطالـــ اطلاعـات حاصـل از متــالورزى

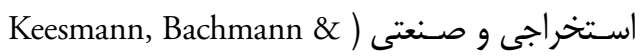
؛Hauptmann, 1985 ؛Hauptmann, 1984b .(Killick \& Fenn, 2012

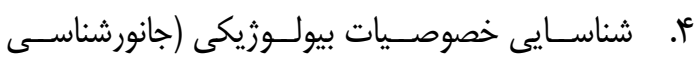

مولكولى و بيو مولكولى) مواد (Hell et al., 2004). ه. شناسايى دانههاى تياهى يا بقاياى مـواد آلى مـورد مورد

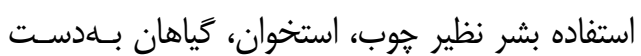

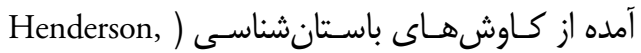

g تحليل و شناسايى ساختارهاى مدفون بـا اسـتفاده از

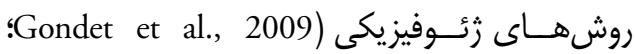
(Ranjbar et al., 2011

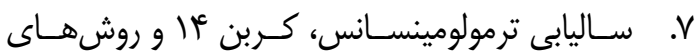
ايزوتويى جهـت تشـخيص قـدمت و اصـالت اشـياء مكشوفه يا موزهاى (Zacharias et al., 2007).

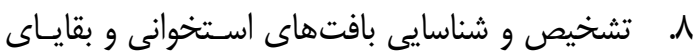

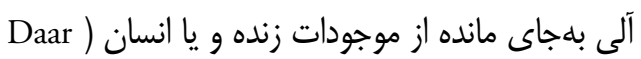

.(Mendoza Cuevas et al., 2015 ؛et al., 2015 
سراميكى بهعنوان يكى از قديمىتـرين صـنعتهـا و و

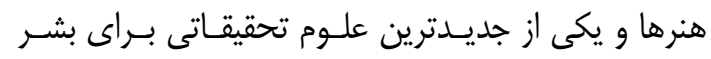
مطرح مىشود. سفال و سراميك و صنعت توليد اين مـاده

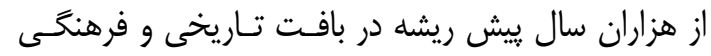

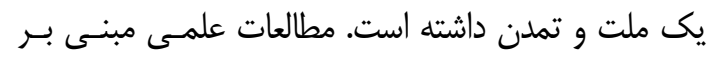

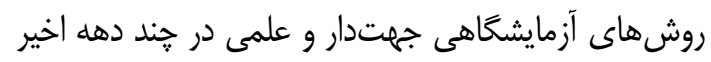

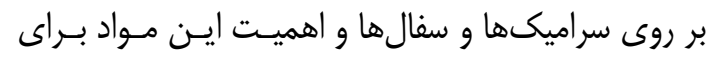

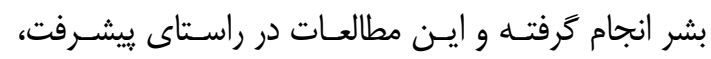

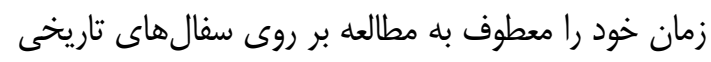

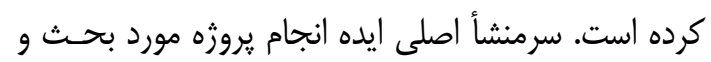

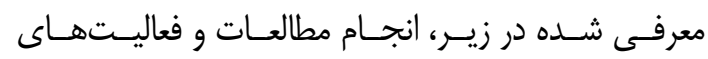
باستانشناسى در جند سال اخير در مناطق باستانى متعلـق

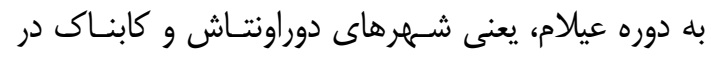

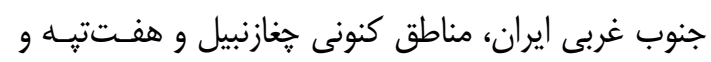

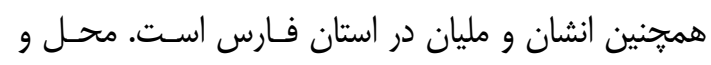
نوع ماده خام مورد استفاده جهت ساخت سراميك و سفال

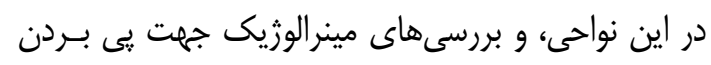

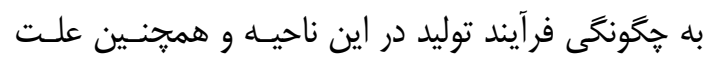

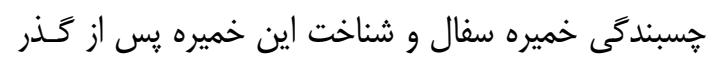

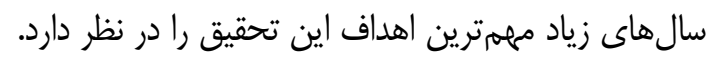
با استفاده از روش هاى سفال نغارى، تكنيك و اسـتفاده از

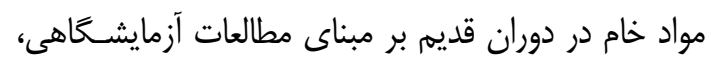

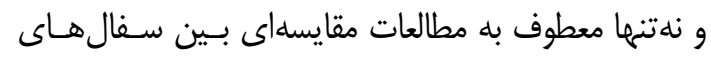

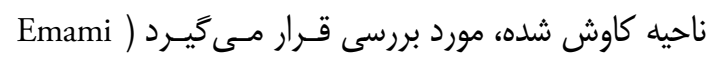

(Emami \& Trettin 2012 2012

عظمت كار حجاران هخامنشى بر روى سـنَ بنـاى

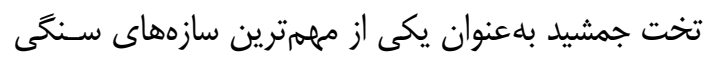

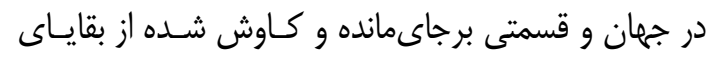

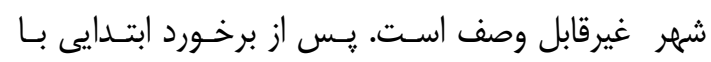

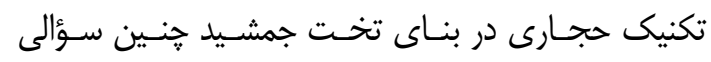

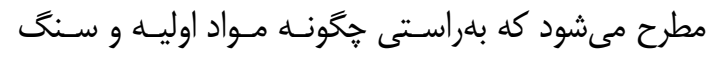

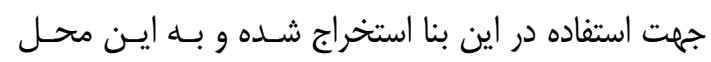

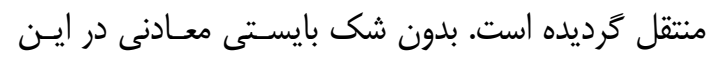

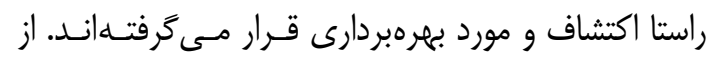

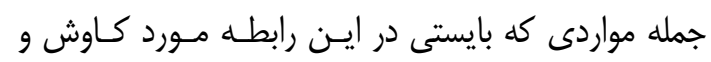

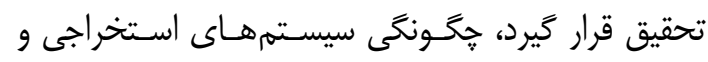

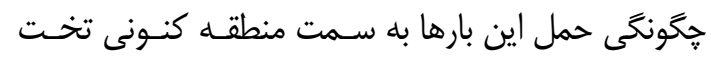

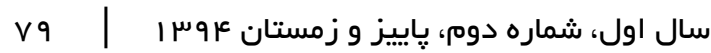

ذوب، سعى در بازسازى و زنـــه كـردن تفكـرات و دانـش

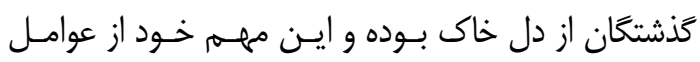

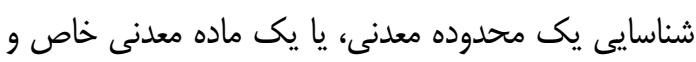

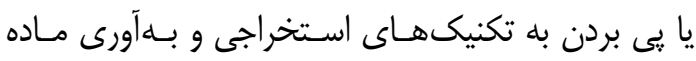

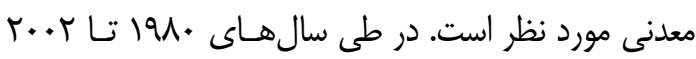

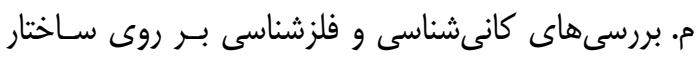

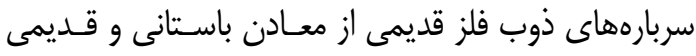

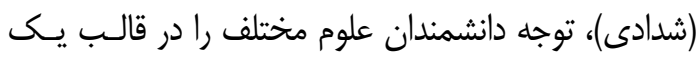

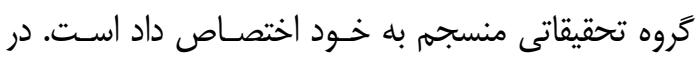

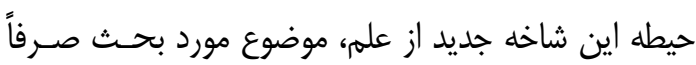

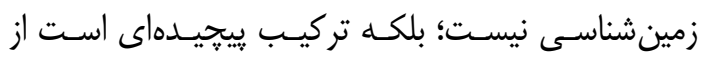

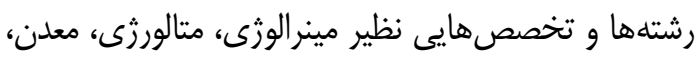

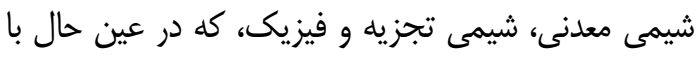

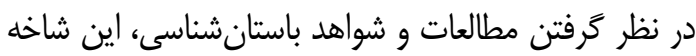

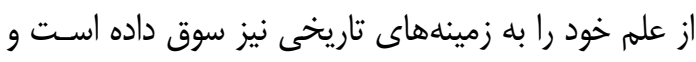

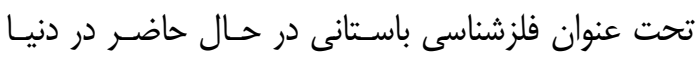

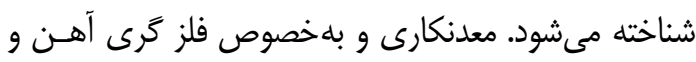

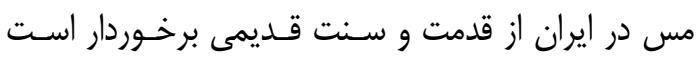

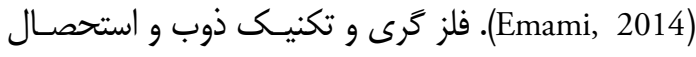
فلزات در برخى از اماكن و سايتهاى باستانى اين اسـتان

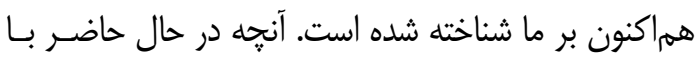

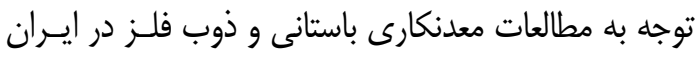

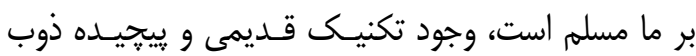

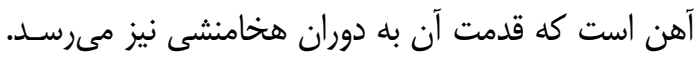

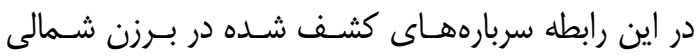

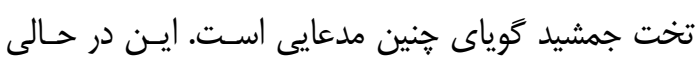

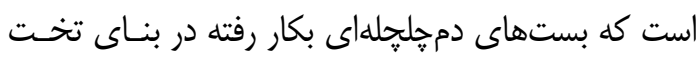

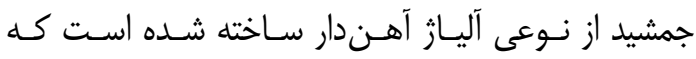

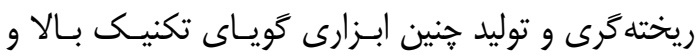

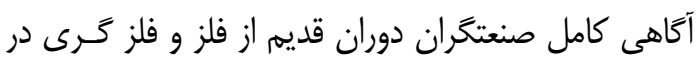

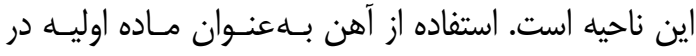

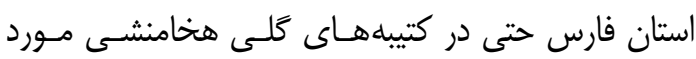

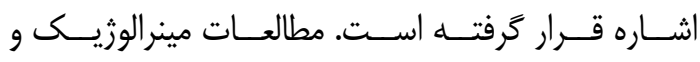

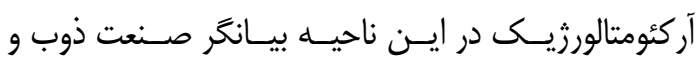

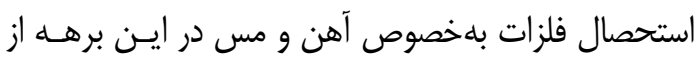

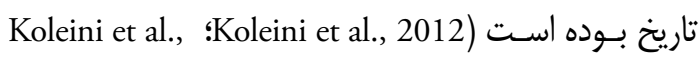


فناورىهاى اتفاقى وابسته به نــوع خـاص مـواد و مصـالح معدنى در يك محدوده مشخص بوده و صنعتآحر اختيـارى

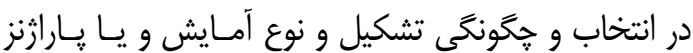

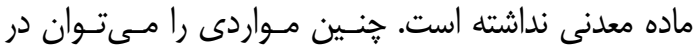
تحقيقات مربوط به استفاده از مس آرسنيكى در هزارهناي

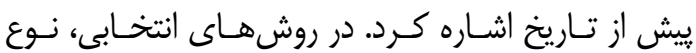
تكنولوزى و مواد وابسته به آن، تحت كنترل خود صنعتخر

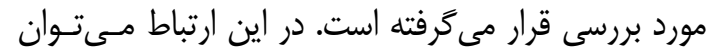

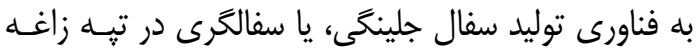

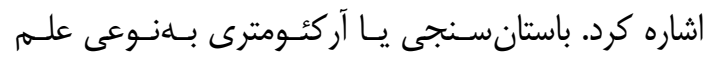

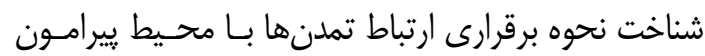

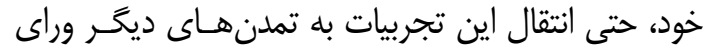

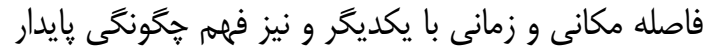

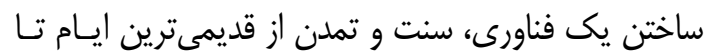
به امروز است. بر اين اساس در خيلى موارد هنوز مشـاهده

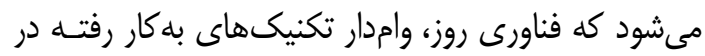
دوران قديم است.

Binford, L. R. (1962). Archaeology as anthropology. American antiquity, 217-225.

Binford, L. R. (1965). Archaeological systematics and the study of culture process. American antiquity, 203-210.

Binford, L. R., \& Sabloff, J. A. (1982). Paradigms, systematics, and archaeology. Journal of Anthropological Research, 137-153.

Bishop, R. L., Rands, R. L., \& Holley, G. R. (1982). Ceramic compositional analysis in archaeological perspective. Advances in archaeological method and theory, 275-330.

Daar, E., Al Mugren, K. S., Chika, S., Barnes, S., \& Bradley, D. A. (2015). XRF measurements of $\mathrm{Zn}, \mathrm{Sr}$ and $\mathrm{Pb}$ in archaeological bone. X-Ray Spectrometry, 44(3), 129-134.

Duminuco, P., Messiga, B., \& Riccardi, M. (1998). Firing process of natural clays. Some microtextures and related phase compositions. Thermochimica Acta, 321(1), 185-190.

Emami, M. (2012). QXRD, XRF and optical microscopy applied to characterization and provenance of ancient ceramics from $\mathrm{Haft}$ Teppeh (1500-1150 BC), southwest Iran. In IOP Conference Series: Materials Science and Engineering (Vol. 37, No. 1, p. 012012). IOP Publishing.

Emami, M. (2014). "Toroud", the late motion for As-Sb bearing $\mathrm{Cu}$ production from 2 nd
جمشيد است. از ديخر نكاتى كه توجه محققين ايـن كونـهـ

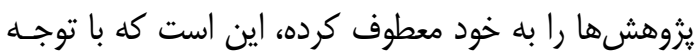
به يراكندگى وسيع معادن سنگ مختلف در محدوده دشت مرودشت، و متفاوت بودن ساختار سنگشناسى ايـن مـواد

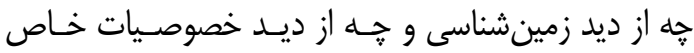

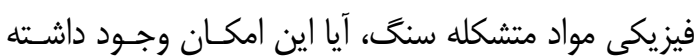
است كه از سنَ خاصى جهت مصارف خاص در سـاخت

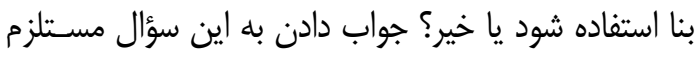

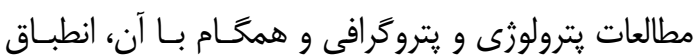
نتايج اين مطالعات با نتايج دادههاى زئوشيميايى است كـهـ اثبات كننده منشأ محلى سنگ استفاده شده در اين بنا بودها است (Emami, 2010). با استفاده از مطالعات زئوشـيميايى سني

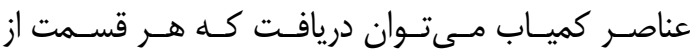

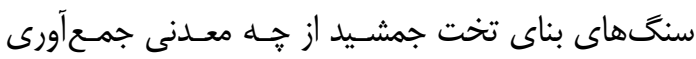

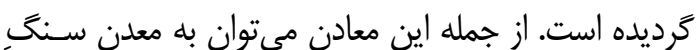

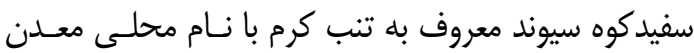
الماس برى، معادن كوه رحمت واقع در برزن شمالى صفه بـ تخت جمشيد و معادن سنگ سياه مجدآباد واقع در كوهى كيى به همين نام در جنوب غرب تخت جمشيد اشاره كرد.

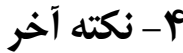

ايران بهعنوان كشورى در شاهراه برخورد تمدنهاى شرق

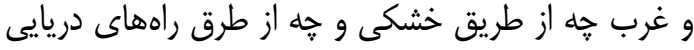

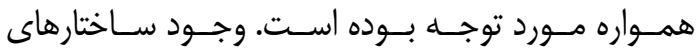
زمينشناسى، جغرافيايى و انسانشناسى بسيار متفـاوت در اين فلات سبب ايجاد گوناكونىهـاى بسـيار متفـاوتى در

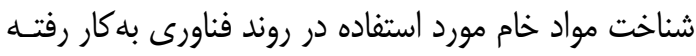
در يك محدوده مشخص شده است. شناسايى تكنيكهاى بلهكار رفتـه در يـك محـدوده مكانى مشخص (در يك برها زمانى مشخص) و شـناخت

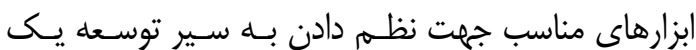
فر آيند توليد از اهداف خاص محققين علوم تلفيقي استئ.

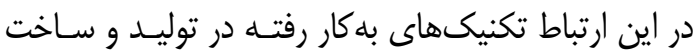
مواد و مصالح بلصورت اتفاقى (Accidental) و يـا تجربسى

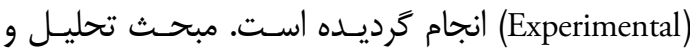
شناخت تكنيكهاى اتفاقى و انتخابى از مباحثى است كـه

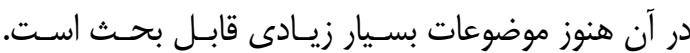

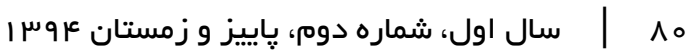


millennium BC in Iran: An archaeometallurgical approach. Mediterranean Archaeology and Archaeometry, 14(2), 169-188.

Emami, M., \& Trettin, R. (2012). Mineralogical and chemical investigations on the ceramic technology in Čogà Zanbil,(Iran, 1250 BC). Periodico di Mineralogia Vol. 81, 3 dicembre 2012, 359.

Emami, M., \& Trettin, R. (2013). High Tech in 5100 BC: multianalytical approach for characterisation of decorated pottery from Tappeh-Zaghe. Surface Engineering, 29(2), 134139.

Emami, S. M. (2010). Preliminary studies on mining methods used in Sivand quarries during the Achaemenian period in Fars province, Irán. Geologia Colombiana, 35, 175.

Emami, S. M. A., Volkmar, J., \& Trettin, R. (2008). Quantitative characterisation of damage mechanisms in ancient ceramics by quantitative $\mathrm{X}$-ray powder diffraction, polarisation microscopy, confocal laser scanning microscopy and non-contact mode atomic force microscopy. Surface Engineering, 24(2), 129-137.

Fernández, J. E., Scot, V., \& Sabbatucci, L. (2015). A modeling tool for detector resolution and incomplete charge collection. X-Ray Spectrometry, 44(3), 177-182.

Freestone, I. (1982). Applications and Potential of Electron probe Micro-Analysis in Technological and rovenance investigations of ancient caramics. Archaeometry, 24(2), 99-116 .

Garrigós, B. I., Ontiveros, C., \& Kilikoglou, V. (2003). Chemical Variability in Clays and Pottery from a Traditional Cooking Pot Production Village: Testing Assumptions in Pereruela*. Archaeometry, 45(1), 1-17.

Giumlia-Mair, A. (2001, September). Iron Age tin in the Oriental Alps. In Le problème de l'étain à l'origine de la métallurgie/The Problem of Early Tin (Giumlia-Mair A. and Lo Schiavo F. ed.), Acts of the XIV th UISPP Congress, University of Liège, Belgium (pp. 2-8).

Gondet, S., Dhemaied, A., Mohammadkhani, K., \& Rejiba, F. (2009). Geophysical investigations in the vicinity of the Persepolis Royal Terrace (Fars province, Iran). ArcheoSciences. Revue d'archéométrie (33 (suppl.)), 69-72.

Hauptmann, A. (1985). 5000 Jahre Kupfer in Oman: Die Entwicklung der Kupfermetallurgie vom 3. Jahrtausend bis zur Neuzeit (Vol. 4). Dt. Bergbaumuseum.

Hell, S. W., Dyba, M., \& Jakobs, S. (2004). Concepts for nanoscale resolution in fluorescence microscopy. Current opinion in neurobiology, 14(5), 599-609.

Henderson, J. (2013). The science and archaeology of materials: an investigation of inorganic materials. Routledge.
Keesmann, I., Bachmann, H., \& Hauptmann, A. (1984, January). Classification of Iron-rich Slags According to the Phase-composition. In Fortschritte der Mineralogie (vol. 62, pp. 114-116). Naegele U Obermiller Johannesstrasse 3a, d 70176 Stuttgart, Germany: e Schweizerbart'sche Verlags.

Keesmann, I., Bachmann, H., \& Hauptmann, A. (1984b). Classification of iron-rich slags according to the phase-composition. Paper presented at the Fortschritt der Mineralogie.

Killick, D., \& Fenn, T. (2012). Archaeometallurgy: The Study of Preindustrial Mining and Metallurgy. Annual Review of Anthropology, 41(1), 559-575.

Koleini, F., De Beer, F., Schoeman, M. H. A., Pikirayi, I., Chirikur, S., Nothnagel, G., \& Radebe, J. M. (2012). Efficiency of neutron tomography in visualizing the internal structure of metal artefacts from Mapungubwe museum collection with the aim of conservation. Journal of Cultural Heritage, 13(3), 246-253.

Koleini, F., Prinsloo, L. C., Schoeman, M. H. A., Pikirayi, I., \& Chirikure, S. (2013). Characterization of the corrosion layer on iron archaeological artefacts from K2 (825-1220 AD), an archaeological site in South Africa. Studies in Conservation, 58(3), 274-282.

Košler, J., Fonneland, H., Sylvester, P., Tubrett, M., \& Pedersen, R.-B. (2002). U-Pb dating of detrital zircons for sediment provenance studies a comparison of laser ablation ICPMS and SIMS techniques. Chemical Geology, 182(2), 605618.

Lichtensteiger, T. (2002). Die petrologische Evaluation Im Einklang mit der Erde (pp. 193208): Springer.

Mannino, M., Thomas, K., Leng, M., Piperno, M., Tusa, S., \& Tagliacozzo, A. (2007). Marine Resources in the Mesolithic and Neolithic at the Grotta Dell'uzzo (Sicily): Evidence From Isotope Analyses Of Marine Shells*. Archaeometry, 49(1), 117-133.

Mendoza Cuevas, A., Bernardini, F., Gianoncelli, A., \& Tuniz, C. (2015). Energy dispersive X-ray diffraction and fluorescence portable system for cultural heritage applications. X-Ray Spectrometry, 44(3), 105-115.

Ranjbar, H., Masoumi, F., \& Carranza, E. (2011). Evaluation of geophysics and spaceborne multispectral data for alteration mapping in the Sar Cheshmeh mining area, Iran. International Journal of Remote Sensing, 32(12), 3309-3327.

Reinhard, K. J. (1992). Parasitology as an interpretive tool in archaeology. American antiquity, 231-245.

Riederer, J. (2004). Thin section microscopy applied to the study of archaeological ceramics. Hyperfine interactions, 154(1-4), 143-158. 
Willmott, H., Miller, I., \& Jackson, C. (2012). Glass Recipes and the Output from a 19th-Century Glass Works: Examples from Percival, Vickers \& Co. Ltd, Manchester. Industrial Archaeology Review, 34(1), 51-64.

Zacharias, N., Schwedt, A., i Garrigós, J. B.,
Michael, C. T., Mommsen, H., \& Kilikoglou, V. (2007). A contribution to the study of postdepositional alterations of pottery using TL dating analysis. Journal of Archaeological Science, 34(11), 1804-1809. 